\section{P16 THE EMOTIONAL STATE IN BRONCHIAL ASTHMA IN CHILDREN}

Olesea Nicu* , Ecaterina Stasii. Department of Pediatrics, State Medical and Pharmaceutical University 'Nicolae Testemitanu', Chisinau, Moldova, Republic of

\subsection{6/archdischild-2019-epa.372}

Background Bronchial asthma is a major public health problem, with an estimated 300 million affected individuals, with increasing prevalence, especially in the pediatric population. Most countries continue to experience a suboptimal level of bronchial asthma control, which requires ongoing optimization of therapeutic strategies as well as improving the nonpharmacological approach. Many asthmatic patients reports high levels of stress and depression. It is known that psychological stress decreases therapeutic adherence and affects the quality of life of children with asthma. The psychological evaluation is important in clinical follow-up, as well as psychological interventions are necessary to complement the pharmacological treatment of bronchial asthma.

The scope of the study was to determine the relationship between stress and evolution of bronchial asthma in children.

Methods There were observed 56 patients with bronchial asthma (10-18 years). The evaluation was included in the questionnaire with complete anamnestic data, clinical features and paraclinical data. The Perceived Stress Scale and Asthma Control Test was used to correlated psychoemotional status and clinical symptoms of asthma.

Results According to Perceive Stress Scale, an average and high health concern level was obtained in 39\% (22 children), all of them were uncontrolled according to Asthma Control Test. Also there were described other potential triggers for asthma exacerbations (house dust mites, molds, polen, etc, and viral infections). Sensitization for house dust mites was attests as well in children with controlled asthma and also in children with low health concern levels.

Conclusion Emotions and stress play a significant role in clinical evolution of bronchial asthma in children. This study demonstrated a strong relationship between asthma and stress in pediatric patients. Use of psychological tools and interventions to increase asthma control are needed.

\section{P17 THYROID STATUS IN CHILDREN WITH BRONCHIAL ASTHMA (BA)}

\begin{abstract}
${ }^{1}$ Tatyana Eliseeva, ${ }^{1}$ Elena Tush, ${ }^{1,2}$ Elena Bolshova, ${ }^{1}$ Andrew Prachov, Viktoria Polyakova ${ }^{1}$, ${ }^{3}$ Ivan Balabolkin, ${ }^{3,4,5}$ Vilya Bulgakova*. ${ }^{1}$ Privolzhsky Research Medical University, Nizhny Novgorod, Russian Federation; ${ }^{2}$ Children's Hospital, Nizhny Novgorod, Russian Federation; ${ }^{3}$ National Medical Research Center of Children's Health, Moscow, Russian Federation; ${ }^{4}$ Central Clinical Hospital, Russian Academy of Sciences, Moscow, Russian Federation; ${ }^{5}$ Pirogov Russian National Research Medical University, Moscow, Russian Federation
\end{abstract}

10.1136/archdischild-2019-epa.373

Background Despite numerous studies, there was no consensus about the effect of thyroid hormones on asthma.

Aims To assess the relationship between the patient's thyroid status and the level of BA control.

Method 51 children with BA were examined, of them 15 girls aged $105.1 \pm 35.3$ and 36 boys aged 114.2 \pm 14.1 months. All children underwent general clinical examination, spirometry, ACQ5 assessment, determination of thyroid-stimulating hormone (THS) levels, free thyroxine (free T4) test, and levels of antibodies to thyroperoxidase (anti-TPO) by ELISA.

Results Elevated TSH levels occurred in 12 (23\%) patients, while all of them had no clinical symptoms characteristic of hypothyroidism, and the maximum TSH rise was $8.45 \mathrm{mIU} /$ $\mathrm{L}$, which made it possible to treat this condition as subclinical hypothyroidism (cGT). None of the patients had an increase in the level of anti-TPO. Another 15 people had a TSH level in the range of $1.16-1.97 \mathrm{mIU} / \mathrm{l}$, the remaining 24 had 2.01-3.74. 18 - had an excess of T4 free, but it was insignificant - a maximum of $23.1 \mathrm{pmol} / 1$ at the upper limit of the norm of $22 \mathrm{pmol} / \mathrm{l}$, and was not accompanied by symptoms of thyrotoxicosis. We did not obtain a clear correlation between the level of TSH and free $\mathrm{T} 4, \mathrm{R}=0.49$, $\mathrm{p}=0.4852$. A weak negative correlation was found between the TSH level and the ACQ-5 score, $\mathrm{R}=-0.29, \mathrm{p}=0.033$. Most often (in 33\% of cases) subclinical hypothyroidism occurred in patients with complete control of BA $(28, \mathrm{TSH}$ $3.39 \pm 1.96)$, and was completely absent in patients with uncontrolled disease progression (5, TSH 1,87 \pm 0.73 ). In patients with partial BA control, TSH levels of 2.0 to 4.1 IU/L $(18$, TSH of $2.93 \pm 1.5)$ prevailed, which may indirectly indicate iodine deficiency. These differences do not reach the level of statistical significance $(\mathrm{F}=1.74, \mathrm{p}=0.1858)$. Free T4 levels were comparable in all groups $(16.57 \pm 1.93$, $16.67 \pm 3.04,15.82 \pm 4.93$, respectively). Despite this, a negative correlation was noted between the level of free T4 and FEV1 $(\mathrm{ml} / \mathrm{s}), \mathrm{R}=-0.42, \mathrm{p}=0.01$. Normal levels of TSH in the group of patients with poor BA control may not be associated with the best thyroid function in this group of patients, but with an inhibitory effect on the TSH synthesis of corticoid hormones (both exogenous glucocorticoids and endogenous - produced by the body on stress - exacerbation of BA).

Conclusion Patients with achieved BA control have a rather high incidence of subclinical hypothyroidism (23\%).

\section{\begin{tabular}{|l|l}
\hline P18 & THE IMPACT OF ATOPIC DERMATITIS ON QUALITY OF
\end{tabular} LIFE IN PAEDIATRIC PATIENTS}

${ }^{1}$ Ecaterina Stasii", ${ }^{1}$ rina Taranets, ${ }^{2}$ Olesea Nicu, ${ }^{3}$ Tatiana Gorelco. ${ }^{1}$ State Medical and Pharmaceutical University of Moldova, Chisinau, Moldova, Republic of; ${ }^{2}$ State Medical and Pharmaceutical University of Moldova, Chisinau, Montenegro; ${ }^{3}$ Mother and Child Institute, Chisinau, Moldova, Republic of

\subsection{6/archdischild-2019-epa.374}

Background Atopic dermatitis (AD) is a chronic inflammatory skin disorder that affects children and may lead to significant disruption in quality of life. In population studies report an overall prevalence of $\mathrm{AD}$ of $2-18 \%$ in adults and about $20 \%$ in children. The impact of AD on children's quality of life (QoL) in US and European countries is relatively well known, though never evaluated in the Moldavian population.

The scope of this study was to evaluate the impact of $\mathrm{AD}$ on the quality of life of children and their parents and to identify the area of patients ${ }^{6}$ lives most affected by the disease.

Methods The study included 78 patients with $\mathrm{AD}$ and their parents. For assessment two questionnaires about the quality of life were applied, the Children's Dermatology Life Quality Index (CDLQI) and the Dermatitis Family Impact (DFI). To evaluate the severity of the disease, the researchers applied the 